\title{
Corrigendum
}

\section{Unlimited Access to Heroin Self-Administration: Independent Motivational Markers of Opiate Dependence}

Scott A Chen, Laura E O'Dell, Michael E Hoefer, Thomas N Greenwell, Eric P Zorrilla and George F Koob

Neuropsychopharmacology (2006) 3 I, 2802. doi:I 0.I 038/sj.npp. I 301058

Correction to: Neuropsychopharmacology (2006) 31, 2692 2707. doi:10.1038/sj.npp.1301008

Dark/Active Phase (lights off)

$$
6 \mathrm{PM}
$$

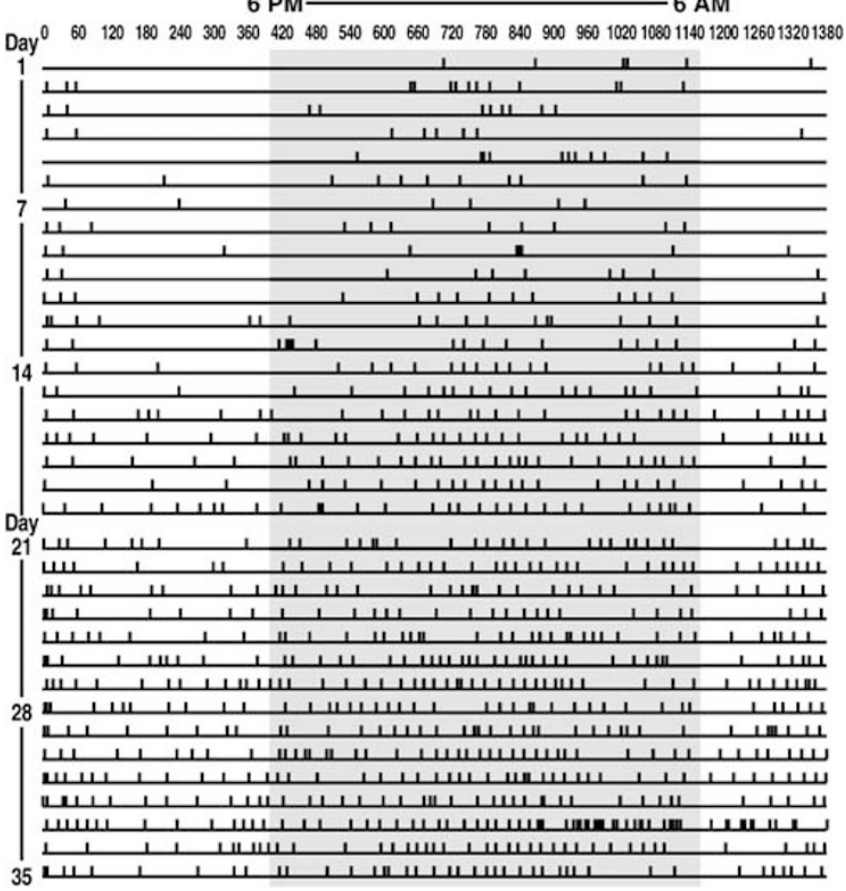

Following the online publication of this article, the authors noted an error in Figure 3. The correct Figure 3 is shown below: 